Florida International University FIU Digital Commons

FIU Electronic Theses and Dissertations

University Graduate School

3-17-2015

\title{
Becoming Other: Virtual Realities in Contemporary Science Fiction
}

Jamie N. Franks

Florida International University, jfran100@fiu.edu

DOI: $10.25148 /$ etd.FI15032123

Follow this and additional works at: https://digitalcommons.fiu.edu/etd

Part of the Other English Language and Literature Commons

\section{Recommended Citation}

Franks, Jamie N., "Becoming Other: Virtual Realities in Contemporary Science Fiction" (2015). FIU Electronic Theses and Dissertations. 1908.

https://digitalcommons.fiu.edu/etd/1908

This work is brought to you for free and open access by the University Graduate School at FIU Digital Commons. It has been accepted for inclusion in FIU Electronic Theses and Dissertations by an authorized administrator of FIU Digital Commons. For more information, please contact dcc@fiu.edu. 


\title{
FLORIDA INTERNATIONAL UNIVERSITY
}

Miami, Florida

\section{BECOMING OTHER: VIRTUAL REALITIES IN CONTEMPORARY SCIENCE FICTION}

\author{
A thesis submitted in partial fulfillment \\ of the requirements for the degree of \\ MASTER OF ARTS \\ in \\ ENGLISH \\ by
}

Jamie Nicole Franks

2015 
To: Dean Michael R. Heithaus

College of Arts and Sciences

This thesis, written by Jamie Nicole Franks, and entitled Becoming Other: Virtual Realities in Contemporary Science Fiction, having been approved in respect to style and intellectual content, is referred to you for judgment.

We have read this thesis and recommend that it be approved.

Ana Luszczynska

Michael Gillespie

Bruce A. Harvey, Major Professor

Date of Defense: March 17, 2015

The thesis of Jamie Nicole Franks is approved.

Dean Michael R. Heithaus College of Arts and Sciences

Dean Lakshmi N. Reddi

University Graduate School

Florida International University, 2015 


\section{DEDICATION}

I dedicate this thesis to my husband, Daniel Betancourt. Without his love, support, understanding, and warm hugs, this would not even exist. 


\section{ACKNOWLEDGMENTS}

First and foremost, I wish to thank the members of my committee. Dr. Ana Luszczynska's interest and knowledge in the various forms of literary theory has been instrumental in shaping the way I read and Dr. Michael Gillespie’s thought provoking questions and discussions have been equally instrumental in shaping the way I think. Dr. Bruce Harvey has been patient, and tolerant, and immensely helpful all while somehow managing to ease a paranoid graduate student's fears. I'm certain I'd be locked in a padded room without these three esteemed persons.

I wish, of course, to thank my parents for not only my existence, but for nurturing my mind and soul. Last, and certainly not least, I wish to thank my husband Daniel Betancourt, the owner of my heart, for standing by my side even when I know I've been completely intolerable. 


\section{ABSTRACT OF THE THESIS \\ BECOMING OTHER: VIRTUAL REALITIES IN CONTEMPORARY SCIENCE \\ FICTION \\ By}

Jamie Nicole Franks

Florida International University, 2015

Miami, Florida

Professor Bruce A. Harvey, Major Professor

The purpose of this thesis was to explore the boundary between human and other created by virtual realities in contemporary science fiction novels. After a close reading of the three novels: Surface Detail, Existence, and Lady of Mazes, and the application of contemporary literary theories, the boundary presented itself and led to the discovery of where the human becomes other. The human becomes other when it becomes lost to the virtual reality and no longer exists or interacts with material reality. Each of the primary texts exhibits both virtual reality and humanity in different ways, and each is explored to find where humanity falls apart. Overall, when these theories are applied to real life there is no real way to avoid the potential for fully immersive virtual realities, but there are ways to avoid their alienating effects. 


\section{TABLE OF CONTENTS}

CHAPTER

PAGE

I. Introduction: The Human Alien .................................................................................

II. Chapter One: Singular Consciousness ……………...................................................

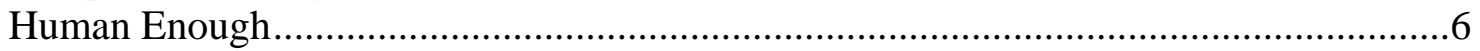

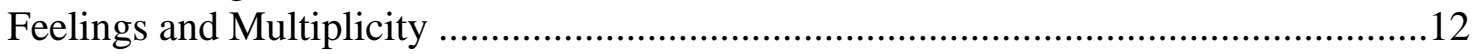

Between Primitive and Obsolescence .........................................................................16

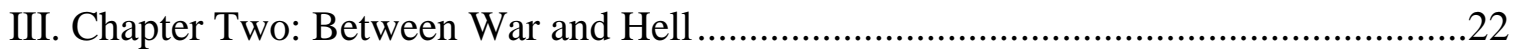

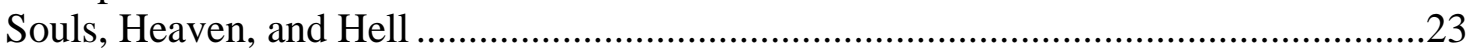

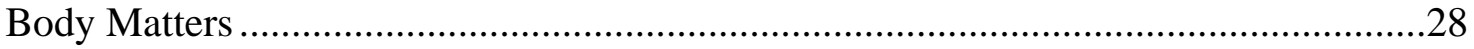

IV. Chapter Three: The Oversaturation of Existence ……….............................................38

From Vanity to Virtual............................................................................................

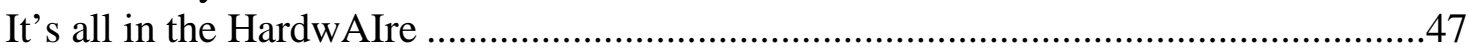

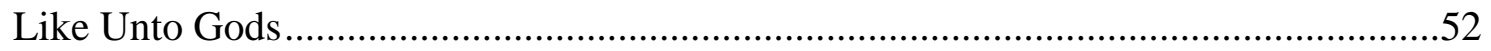

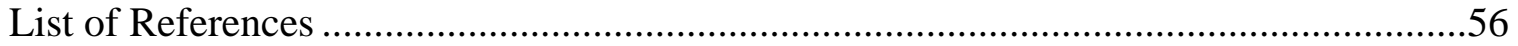




\section{Introduction: The Human Alien}

Aliens are as necessary to science fiction as oxygen is to human beings. Without the promise (or threat) that we are not alone in the universe, the genre would not be as prevalent as it is today. Often, aliens act as vehicles representing the angels and demons of human nature, or to bring our worst fears as a species to life. They are easy monsters or gods, allowing us to blame outside forces for our own shortcomings, and ultimately to teach lessons about what we must change in ourselves to make the world better. Alien stories are today’s cautionary fairy tales.

The word "alien” has its roots in ancient words that mean "to make strange or foreign.” To be alien is to be foreign, strange, estranged, isolated and inhuman. To alienate is to cause someone or something to be the alien and all that the word implies. Science fiction does have a lot to say on the subject of beings from the outer reaches of space, but there is a different sort of alien story that never reaches beyond the atmosphere. These are the stories in which technology, especially virtual reality, plays a major role.

Virtual Reality is not a new idea. Most people living in developed nations have experience with cyberspace. Virtual worlds offer a kind of anonymity that is almost nonexistent in other media. As the popular meme goes: “On the internet, no one knows you're a dog.” No one knows anything about you that you do not explicitly tell them. You can be anyone, or multiple anyones in as many different places as your computer's processor will allow. There is something powerfully dangerous about the kind of power anonymity offers, and something equally dehumanizing about it. It is no wonder that 
science fiction has latched on to such an incredible and terrifying invention of the human mind to create this new type of alien story.

Science fiction takes cyberspace beyond the contemporary screen and (optional) keyboard. Most cyber-thrillers or even vague mentions of virtual worlds offer a much more immersive and interactive experience. With the right equipment, denizens of these futuristic landscapes can physically and mentally experience any environment they can dream up. Often, the ability to experience whatever the human imagination can dream up leads to the kinds of dire consequences seen in the works of William Gibson or other providers of cyberpunk fiction. The mass alienation of the human species is, more often than not, among these consequences. While cyberspace and VR theoretically make communication across vast distances much easier, thus bringing people closer together, the truth is that VR seems to cause people to become more closed off from each other in favor of the worlds they've created for themselves from a computer chair.

The original idea behind such advanced technology is to create a society of freer, more fulfilled citizens who are the maters of their own fates and identities. In her book Representations of the Post/Human, Elaine Graham states:

It is argued that contemporary digital technologies, such as virtual reality, are merely a continuation of human capacity for tool-making. What may seem unfamiliar and threatening is but an extension of perennial skills, serving not to undermine or expunge the human, but to enhance it, as tools have always done (185).

In order to create a society of citizens who are the masters of fate and identity, humans must create the tools that allow them to do it on a massive scale. Since the beginning of 
time we have created tools to enhance our experiences and make our lives easier. The principle of creating virtual realities should not be viewed any differently than the creation of the wheel: we are enabled by both to travel vast distances in far less time than it would take to walk. The world becomes a smaller place. Physical, linguistic and mental barriers can be more easily crossed or completely broken down with each new thing that is created and introduced into the human experience. What we must remember, though, is that when someone is hurt using a tool, it is never the tool's fault, but the wielder's.

It is easy to blame a gun for killing an innocent or a bomb for leveling a city. Behind those guns are bombs, though, there is a human being pulling the trigger or pressing the launch button. Likewise, video games and the oversaturation of images and things on the Internet are often blamed for school shootings or excessive violence. In reality, however, the only people who should be blamed for our faults and shortcomings as a species are ourselves. VR doesn’t isolate and alienate people; people isolate and alienate people.

Karl Schroeder’s Lady of Mazes, David Brin’s Existence and Iain M. Banks’ Surface Detail all prominently feature Virtual Reality. Each narrative presents it differently. The concept of VR stays the same, whether it is fully immersive or just an overlay, it is always a digital, computer generated space where almost anything is possible. Speculatively, Graham says, virtual reality serves the “desire to 'become (like) gods’ by striving towards semi-divine status and knowledge” (Graham, 170). In every single cautionary tale told through time, the mortal who tries to become like a god always fails. Hubris gets in the way of accomplishment and characters make foolish mistakes. 
True, lessons are learned at the ends of these tales, but always at the expense of the boy who flew too close to the sun.

Each of the three narratives features a different dehumanizing aspect to the way their virtual realities are used and/or how they are accessed. Lady of Mazes and Surface Detail both require implants connected directly to the nervous system for access to their respective virtualities, automatically creating cyborgs, something that is both more than and less than human. Virtual Reality is always accessible in Lady of Mazes, but in Surface Detail the only looks the reader gets into their virtual worlds are either after the use has chosen to "die" or if the user is engaged in the ongoing war between those who advocate for the existence of virtual hells and those who do not. The VR in Existence is not as fully immersive as those of the others, but access to it seems entirely dependent on wealth and location, creating a deep rift between those who "have" who are alienated via their own virtual overlays and those who "have not" who are alienated via their lack of connection with the rest of the world. The world itself, though represented as heaven, or a personal immersive haven, or a simple overlay that paints flowers on everything you walk by offers is only limited by the user, but when the user is limited by the mores of his society and further, his species, the fearful prospects of alienation and oppression are disturbingly plausible and often even come to pass in these narratives. In short: Humanity has no one to blame for its ultimate mass alienation but itself. 


\section{Chapter One: Singular Consciousness}

There has not been much criticism done on the texts of Karl Schroeder. His body of work deals in the far future and often touches on deep, philosophical themes. It is Space Opera in the vein of Iain M. Banks as evolved from the cyberpunk of William Gibson: absurd technological proportion paired with sprawling dystopia. Without a doubt, the technologies in Schroeder's novels are just as incredible as any other text that falls in the Space Opera genre. However, the way in which he implements these technologies in his narrative is unique, if not downright bizarre.

Schroeder's 2005 Lady of Mazes, a prequel to his first novel, Ventus is set in the far future between a man-made free floating coronal in the Lethe Nebula and another larger habitat located somewhere near Jupiter. Man has colonized the galaxy and has reached the point of post-scarcity. Virtual Reality, hedonism, and general anarchy (for lack of a better term) take on a much darker tone than they do in the Culture series. Certainly, lawless society never hurts anybody in the free-for-all, hedonistic future.

The novel follows Livia, a native of the Teven Coronal in the Lethe Nebula. When the coronal is violently attacked by an enemy no one seems to know anything about, she and her companions leave the nebula to seek help from the Archipelagoruling body of the Local System. Because the Lethe Nebula has grown outside of the Archipelago's jurisdiction, no one there can do anything to help. Ultimately, the antagonists win and are ultimately defeated in Ventus: a novel where technology, specifically AI, goes horribly wrong. The novel and its sequel tell a tale of humans trying to live human-sized lives in a future that has long outgrown them. Humanity, of course, wins in the end, but not without paying a significant price. 
Lady of Mazes is, perhaps, more serious minded than the Culture, but perhaps not so serious minded as Existence. The novel does use virtual reality in relation to the loss of the sense of the human self. Traditionally, humans only have the one consciousness unless they have been diagnosed with a serious mental disorder. Lady of Mazes explores the idea of casting a single consciousness out via virtual reality. The personality retains its singularity, but in multiple forms in various situations. The novel also explores the role of AI with regard to human consciousness and humanity in general. The technology has shifted so that the human psyche can be replicated to a potential infinity, ultimately rendering humanity as helpless as a stone on the beach: doomed to be moved, eroded, and eradicated on the whims and tides of artificiality.

\section{Human Enough}

Conveniently, Lady of Mazes, gives us the definition of a baseline human in its protagonist, Livia Kodaly. She is subjected to what is called a "cliff test" and passes it, proving her ultimate actual personhood. During a cliff test, the human in question is subjected to a virtual reality where they are suddenly falling off of the ledge of a very high cliff. The point is "to see whether you still have normal human responses to threat situations. Most Archipelagics who suddenly found themselves hanging from a cliff would assume it was just another inscape experience, and would not struggle. They would have had no adrenalin reaction,” because “they don’t have the experience of a stable and dangerous reality to ground them” (Schroeder, 151). Basically, the people of the Archipelago, a man-made, free-floating structure somewhere near Jupiter, have become so inundated in the safety of their virtual worlds that they no longer accept that their surroundings could possibly hurt them or affect them in any negative way. They 
exist in a safe bubble of humanity where virtual reality, or inscape in this narrative, provides for them via neural implants where, as Elaine Graham puts it, "truth and reality are indistinguishable from illusion or simulation” (Graham, 191). Archipelagics have no fear of falling off of a cliff because the implant ensures that they not only avoid potential cliffs, but also something as mundane as running into another person. As we learn in an overheard conversation, "more than nine tenths of all our thought and action is unconscious... why should such petty issues as avoiding tripping over somebody be allowed to take up the last fraction” (Schroeder, 133)? The people living in this world have no concept of material reality. In a crowded shopping mall, people must see each other and move out of the way. When that is taken away, and an implant allows you to ignore the existence of all of those other people, there is not really that much left but the virtual world painted onto our consciousness.

'Other,' in this setting is a creature, human by its biology alone, which no longer displays its fight or flight response. It has become complacent. There is no actual conflict or danger in its life. Virtual reality seeks to make its life seem meaningful and succeeds, at the expense of actual human perseverance and integrity. These beings which do not pass the cliff test are no longer human, they simply exist. If they want to fall off a cliff or experience being poisoned or attacked by a polar bear, they can, but they all know it is always just a simulation that can be turned off once they get too scared or bored with it to continue on. Humans, in this narrative, have become prosthetic: plastic representations of what used to be living parts. Margrit Shildrick claims, "The human body can be manipulated, extended or substituted seemingly without limits” (271). The body, as malleable as it is, can be manipulated before and after it becomes vacant of all thought, 
but not so much that biological death occurs. Since "uncovering the inherent plasticity of the body and its multiple possibilities of transcorporeality," is incorporated into the culture of constant virtual reality via combining the "organic [the body itself] and inorganic non-self matter [neuro-implants], such modes of corporeal transformation can comprehensively undo the conventional limits of the embodied self" (Shildrick, 270, brackets mine). Clearly, with something like the cliff test acting as a common standard by which humanity is judged, the conventional limits of the embodied self are no longer relevant.

There are those on the Archipelago who abandon the comforts of constant virtual reality for what is colloquially called "crippleview," where "cripple” is defined as not using your neural implants to influence the world around you to whatever you think it should be. While waiting for his companions to come to their senses and remember their mission (asking for help from the Archipelagics), Qiingi, one of the main protagonists, meets a pair of girls, one of whom shares her story with him. In her narrative, the true nature of the comfortable lie of virtual reality is revealed. Ishani begins her story by telling us that six generations of her family all lived together on an estate in a coronal. This is not remarkable by itself; after all, trillions of people live on coronals, free-floating rings in space made by people for people. She tells the story of how her friend Charon, aptly named for the rower on the River Styx, begins to guide her towards the death of her worldview:

He came to see me in my studio one day—I was a pretentious little girl and fancied myself a painter. I'd had a real studio built for me by the house bots, high up in one attic of the main building. I wore and old-style 
Parisian painter's cap and a white smock while I worked, even though I would never in a million years have touched real paint. I was working in airblocks when Charon came in, moving sculpted shapes of opacity and colored translucence around to create a light sculpture... Charon took one look at me, and burst out laughing (177)

On its own, this is just an innocuous young woman in the awkward teenage stage of trying on different faces to find herself. In the less extreme cases of contemporary media, there are hundreds of teenage girls just like this, resisting social reality to try to find their own ways through life. The story continues, however, when Charon says to Ishani, "You're not much more real than that stuff you're playing with, are you?” Ishani plays it off, but Charon continues, ultimately opening a virtual window:

Visions unfolded in that window like flowers opening in the sunfirst dozens, then as Charon's query raced through the worlds of the Archipelago, hundreds, thousands of subwindows floated in an infinite space next to my sculpture. They rotated in and out of focus at the front of the field. And, in each of them, a young woman stood in front of a halffinished light sculpture.

"This is what's happening right this second, all across the Archipelago," said Charon, "I simply asked inscape dot show me all the publically accessible feeds from girls who are working with airblocks.” After all, in a universe of trillions it is entirely reasonable that any number of teenage girls are trying to create art in various environments: 
"It gets better," said Charon, “Let’s do a query on how many of those sculptures are just like yours.”

"Stop,” I said, but he went ahead with it, opening a second window—and there they were, dozens of girls making my sculpture.

"And even better," he continued, enjoying the look of horror that must have stolen across my face, then, "let's see how many of those girls are being mocked by a friend who's doing queries next to their work-“

The odds do not favor us finding two teenaged girls drawing the exact same picture in the same exact environment at the same exact time in the contemporary world. Once human numbers begin to reach into the trillions, finding two such girls becomes slightly more possible. Charon does us the service of clarifying:

You're a wallpaper, Ishani. You can't have a thought that a million other people aren't having, you can't do anything that a million other people aren’t also doing. It doesn't matter what you say or whether you live or die because a million other you's are there to take your place (177-8).

The reveal of her status as wallpaper is not what ultimately disturbs Ishani to the point of moving her life to crippleview, however. She got over it, "Several months later, the whole incident had receded and become trivial,” she says. She encounters Charon once again, who is not surprised that she does not care or does not remember the shock and horror she felt, "Your narrative steered you away from the edge of that cliff," he explains, "That's what it does... the great commandment of the narratives is that your life must be meaningful... if knowing the truth strips the meaning away, then the truth must be suppressed" (179). Technology has found a way to see to it that every life feels as though 
it has purpose and meaning. However, when everything has meaning in the same exact way, meaning ceases to exist. Actions become robotic, people and those who identify as people just begin going through the motions, whether consciously or because a high and mighty AI brain has predetermined the meaning in their lives. Citizens of the Archipelago are allowed to follow their dreams in an absurd final realization that everyone is a special snowflake meant for great things. Ultimately, this system renders the reward from working for your goals completely meaningless. There is never the chance of failure and growth from failure, creating stagnation and priming the human species to fade into nothing. Almost no one in this universe even realizes that they are, as Charon so eloquently put it, just wallpaper: looked at, discarded and very easily replaced. They are all leading such meaningful lives that they are now completely meaningless and obsolete. Meaningful lives become like fashion accessories, they are exciting when they are new and different, but become commonplace, boring, and largely meaningless once everyone begins using them.

In the process of advancement, humanity is lost and people just become moving parts in a machine that no longer has any purpose. There is no longer anything to work for, there is no longer any such thing as conflict or progress. Emotion must be earned through torture and even then only let out during key events of a person’s life. If lives even have individual key events anymore. Everyone is given a purpose that they have not earned, every life has meaning that is not worked for. When nothing is earned, nothing is gained and nothing changes. 


\section{Feelings and Multiplicity}

After a catastrophic event on one of the Archipelago’s coronals, Livia is brought to be the baseline human to soothe the survivors by her mere presence. When she is uncertain of what exactly her role is, the Government, an AI, assures her that she is already performing her role. “They see something they may never have seen before,” the Government explains, “a normal human reacting normally to a traumatic situation” (Schroeder, 159). Humans, or perhaps post-humans who were seeking something more on their small man-made world, are so out of touch with reality that their instincts are simply gone. All the affected humans need to do is see Livia having normal human responses to a traumatic situation and they can begin to regain their hold on material reality. It reminds them that no, everything in the universe is not supposed to feel or be "good” for whatever value of the word you hold. It reminds them that "good” only has meaning if there is "bad" or "stressful" or "traumatic" to compare it to. A grand statement, to be sure, but it seems that some kind of balance must be maintained in order for humans to be human.

Here and in The Culture, VR is a realm of unmitigated pleasure. People like to do things that make them feel good. In a post-scarcity society, chances are that the hierarchy has “disappeared” and melted into something resembling egalitarianism. That is, everyone has access to the endless playground that is virtual space. Automatic access to the id’s desire is not only lazy, but immeasurably dangerous. Every virtual narrative comes to the inevitable point where unrestrained pleasure has become boring and the violent aspects of human nature (for lack of a better term) have begun to take hold. 
Virtual pleasure becomes the virtual need to cause pain, or to be in pain, or to wage war or commit violent crimes.

Even though violence is an unavoidable part of any VR narrative, it is always frowned upon and it is always "hidden.” Violence is relegated to the deep corners of cyberspace and locked under pass codes and firewalls that stop exactly no one who is willing enough from gaining access. In corporeal space, pain is a given part of existing. It serves as a sign that we are alive and offers something to make us grateful that things such as “pleasure” or “joy” exist. Once there is an option for a body to no longer feel pain, it would choose not to feel pain as long as it did not mean death. Yet, VR narratives always include virtual dens of iniquity where some violence is done to a questionably willing victim. Lady of Mazes, is no exception.

Still, there seems to be a need for actual emotional authenticity in the Archipelago. Take Sophia Eckhardt, for instance. Upon the first mention of her we learn that she has "tattoos, apparently physical” (Schroeder, 130) which is unusual enough in this setting. Learning why she has actual, physical tattoos is what drives the way of life in the Archipelago home. Sophia is a musician, or soundtrack on the Archipelago, but not just any soundtrack:

The tattoos were apparently proudly-born marks of an ordeal Sophia had undergone years ago. In a carefully constructed virtual world... she had allowed herself to be starved, tortured, and terrorized for weeks. She had emerged with anxiety and rage, her days full of bad memories and flinchreactions. With the use of drug and neuroimplant therapies she could easily partition off that side of herself and live a placid life. But when she 
performed at assigned times in other people's narratives she let it all out, and her rawness and pain lent emotional power to whatever key event was occurring in the person's life (135).

In other words, what is termed in contemporary jargon as "life experience" must be crammed into a few torture-ridden weeks just so a songstress can put some real, raw emotion into her music. This implies that actually feeling something, or having things that evoke strong emotion or at least possess strong emotional value still have a place in a post-scarcity, post-hardship society. What is disturbing is that hardship has to be simulated. The reader is not privy to many of the details of Sophia's time in whatever virtual hell she was subjected to, all we know is that she had to be subjected to some sort of hell in order to be able to feel again. Even more disturbing is the fact that she is called a "soundtrack," a term that applies to ambient background noise in visual media. Sophia has willingly put herself through hell to be relegated to the background noise of other people's lives.

It is not all doom and listless drones, however. Teven, Livia the baseline’s home, is separated into what are called manifolds, the Lady of Mazes term for societies or cultures. While manifolds act somewhat like countries insofar in that they all occupy a different space on the coronal, they are also dictated by the virtual world. All citizens of Teven have neural implants which enable a technology called inscape. Inscape provides the virtual reality overlay in the physical space of a manifold. The technology and visuals that are available to any citizen are directly dictated by tech-locks, which communicate with the implants and enforce a manifold's way of life as soon as the borders, called horizons, between them are crossed. The culture that we spend the most time with on 
Teven in is the highly technological, Neo-Victorian Westerhaven and the tribal forest where Raven's People dwell. In Westerhaven, society relies on the use of avatars, called animas. Animas are physical manifestations of multiple identities, hauntingly reflective of Graham’s argument that “the unitary face-to-face self is superseded by the multiple self” (Graham, 5). While the virtual world allows us to pretend to have multiple personalities across digital media, the animas in Westerhaven all share one personality with their hosts.

Any individual can have any number of animas doing any number of things on their behalf. They are manifestations of the personalities of those they represent and are able to make decisions in the stead of their physical counterparts. People in Westerhaven know when they are talking to an anima, but it does not seem rude or even unusual to leave an anima or enter one mid-conversation. Contemporary virtual communication is largely still faceless. However, programs like Skype and FaceTime are becoming increasingly more popular. So it comes as no surprise that VR stories, Lady of Mazes in particular, have cycled back into a form of embodied communication. Graham notes, “forms of virtual interaction retain many of the conventions of face-to-face community" (Graham, 189). Societies in this narrative have taken virtual interaction to the extreme in their execution of virtual communications. There is a need in human communication to be able to "read" what the other person or persons are feeling based on their facial expressions and their tone of voice. These things are difficult to communicate over text, it is only natural that an alternative might be found and explored within the realm of science fiction, and especially within the realm of immersive virtual reality. 


\section{Between Primitive and Obsolescence}

Most important about the way Teven operates is the compromise it enforces between physical reality and virtual reality. While places like Westerhaven rely heavily on technology to forward their diplomatic goals or to hide their emotions from their peers, physical presence is still important. In the beginning of the novel, the protagonist Livia Kodaly must go through the conversations her animas engaged in to learn what she might have agreed to the night before. She learns that she fought a duel on behalf of a man she hadn't realized she was attracted to and lost. While musing on what she would have done if she'd actually been there in person, she comes to the conclusion, "If her anima had fought a duel, then Livia herself almost certainly would have done so had she been there in its place. Animas might only be imitations of people, but they were very accurate imitations” (Schroeder, 11). It is taken completely for granted that any decision an anima makes is automatically the one that the physical person would have made. There is no questioning that an AI might be flawed, or that it might develop its own personality traits. Livia has a brief moment of questioning it, and immediately brushes it off. The technology that replicates her personality canot possibly be incorrect. She would have fought the duel whether it was her physical presence there or not, no matter what the consequences are to diplomatic pull and credibility.

Personalities can be so easily imitated that even the original is convinced that the replications make correct decisions in their stead. It is taken for granted and clearly not even worth a thought. The easy copy and pasting of personalities is troubling. After all, what use is there for the original consciousness if it can so easily be imitated? It is true that animas are made via the neural implants. However, there are also agents. These are 
independent personalities that the neural implants paint on the user's senses. In Livia's case, they appear as fairies named Peaseblossom and Cicada. These agents are AIs which can, and often do, summarize the exploits of Livia's animas from the day before. Livia can then relive the conversations or events on her own, or she can request that they do it for her and they will give her the highlights of her evening. It is remarked that they are painted onto her senses. Later, however, the agents find a way to acquire actual bodies of their own to occupy corporeal space. The novel implies that the same level of technology is available on Teven. It could be, then, that rampant AIs could take over, somehow, and no one would even know what was happening.

It is strange when we consider how the very existence of animals might change the nature of a thing as commonplace as conversation. A person does not have to be physically present in body or mind to speak with another person. Jean-Luc Nancy's statement, "where we are, amounts to nothing more, perhaps, than a reflection, or floating shadows” (Nancy, 4) is given an entirely new meaning in a science fiction context. Already, in Nancy's words, we are ghosts of ourselves even as we allegedly exist in a corporeal reality. Even so, we cast ourselves out into the virtual world and become words on a screen, a reflection of a ghost. Lady of Mazes pushes it into the future, casting the human soul back into a physical form in a thousand different directions in a thousand manifestations - a shadow of a reflection of a ghost; one that is allowed to make conscious choices when the original consciousness doesn't even know where the body stops and thought begins.

The concept of animas seems like a natural evolution given that the very idea of phone conversations is that one person does not have to be there bodily in order to talk to 
another person. After all, “we're obsessed with showing a this” (Nancy, 3), and we cannot show a this with the present invisibility that distant communication currently entails. The need to see and interact is shown even now with video-chat mediums such as Skype or Face Time. The difference between current video-chat technology and the scattering of shadow-copies of one's self is that it is incredibly difficult to pretend to be a different person when your partner in conversation can see and read your face. In a textbased internet chat room, anyone can take on any identity, anyone can be scattered in thirty different chat rooms and attempt to be thirty different people. The concept of animas is more of a direct evolution of the idea of the computer chat room, save that the animas can only act upon the decisions that the core mind would probably make in any given situation. Like Livia, one person can hold thirty different conversations about thirty different topics at once. The difference is the bodily presence, there is always a body called Livia, which usually looks like Livia, to look at and talk to and even touch or duel with. Livia’s original brain can only be with her original physical body. However, each anima has a simulation of Livia's original brain, or at least a good enough imitation that Livia takes it for granted that her animas make absolutely correct choices in place of her original self.

Livia does not always have to look like Livia, either. Besides the manifolds imposing technology limitations on a society, they also sometimes impose different appearances. In a manifold called Blockworld, for instance, everyone appears as a cartoonish caricature or animal rather than a human being. On a smaller scale, in manifolds where animas are allowed, animas can appear any way the original wants them: including wearing different clothes, having different eyes or hair, uglier or more 
beautiful or even as the opposite gender. If you had never met any Livia before, and a male anima version of her approached you for conversation, the only thing you would really know for sure is that you were talking to an anima. There is nothing to suggest that Livia’s original form jumping into the anima would do anything to disrupt whatever illusion the anima is presenting. There is clearly an acceptable level of dishonesty among Westerhaveners on top of the blind trust that the AI will not become self-aware and terminate humanity. Or, at the very least, begin playing uncharacteristic pranks on each other. They are, after all, "very accurate imitations.”

Control over presenting oneself gets even more specific and probably even more political. During any given interaction, Livia and others of Westerhaven can have masks, which can show a pleasant smile or an emotionless façade if the person behind wishes to hide the emotions on their faces. Diplomacy is incredibly important to the culture of Westerhaven, it can be useful to hide surprise or amusement if showing it will cause a diplomatic incident. However, venturing outside of Westerhaven, we find that there are societies that value the purity of true emotion and do not allow masks or animas. You must always only be an original and however you emote, no matter the diplomatic consequences, is what you are stuck with. Conversation in general is difficult when one person canot gauge how the other is feeling based on their facial or body expressions. Imagining conversation with what is essentially an $\mathrm{AI}$ imitation of a supposed real person which is also able to hide its emotions behind a mask is frightening. While people in Westerhaven will always seem to know the difference between an anima and the real thing, it does not seem to matter in the face of sincerity. In fact, in places like Westerhaven, sincerity seems to be a thing of the distant past. 
Westerhaven seems excessive with respect to the more low-key and less politically inclined societies It should be remembered that no one is bound to the manifold in which they are born. If one does not like the two-faced diplomatic ways of Westerhaven, they can move after their horizons are literally expanded at adolescence. When a resident of Teven comes of age, the horizons that keep the manifolds separated are dropped, allowing unimpeded exploration of the surrounding world in order to find where you feel you belong and where you can lead a meaningful existence. All of this technology is available: the ability to create digital copies of a person, the ability to protect from pain or death or disease, the capability of curing all birth defects in the womb. Yet humans still feel they need to lead meaningful, human-scale lives. Not only that, but it is much easier to find a place to lead such a life when infinite possible societies exist that will allow you to keep to your values. Meaning can be found in how closely we, as individuals, hold to the values we create for ourselves. Rather than being forced to keep to those values in the face of adversity, the environment provided on the Teven Coronal makes it easy: no adversity, you live in your mostly perfect society with people who mostly agree with you.

This is not to say that there are not any disagreements. War exists for the people of Teven, though the one we are privy to between Westerhaven and Raven's People is “Only in the gamers' submanifold. It’s purely voluntary" (Schroeder, 21). So within the manifolds, there are further divided manifolds that no one has to take part in. If someone from Raven or Westerhaven wants a good war to relieve their stress, all they have to do is $\log$ in to this submanifold and they get the experience of war without all of the death and property damage. It is never really revealed what the war is about, aside from a vague 
statement that, "there have always been lands that are not strongly real for either of our peoples” (Schroder, 54). So there seems to be some trouble with deciding how far the manifolds spread in the physical world, at least in some places. The war, though, only seems to be important for a few people. Some on both sides feel that physical space is worth fighting over, but if others want nothing to do with it, they do not even have to see it or pay any attention to it. Ultimately, when there is utterly no need for any sort of conflict to occur, people must create their own conflicts in order to make their choices more meaningful. At the same time, any conflict, such as a war or a diplomatic incident that someone does not want to experience can be ignored so thoroughly that it might as well not even exist. 


\section{Chapter Two: Between War and Hell}

The Culture series, written by the late Iain M. Banks, falls into the Space Opera genre. The series has all of the Space Opera tropes: melodrama, adventure on the grandest scale, and incredible technology that might as well be magic. The titular Culture is a post-scarcity and post-law society. Citizens live in indolent comfort and are allowed to, in general, do as they please. Stories about people who can do what they want with little to no consequences would not be interesting to read. Thus, Contact exists. Contact is the branch of Culture which deals with alien societies. The stories end up being about the adventures of the Contact agents and the aliens they are trying to integrate or defeat.

Packed within the ridiculous and unlikely levels of technology and the equally ridiculous adventures of the protagonists, are interwoven commentaries about the human condition. Banks’ commentaries include basic human rights, the existence (or not) of the soul, and attempts to find what it means to exist as a sentient being in the universe. Each novel encompasses a different theme, mixing pulp-like adventure with the "serious" questions that more "serious" literature tries to answer (or even ask) in a more "serious" way.

Chapter Two examines the questions extant within the penultimate of the ten Culture novels, Surface Detail. Briefly, Surface Detail covers a murder, revenge for said murder, a war in heaven, and virtual reality. Thematically, it deals with the soul, with ownership, with the increasing importance that the virtual world has with regard to the material one, and perhaps most importantly with the body. However, in spite of Surface Detail focusing largely on cyberspace and virtual reality, this installation in The Culture series still qualifies as space opera rather than cyberpunk. That is to say, while the other 
novels I cover might portray a more pessimistic view of the way direction things are headed, The Culture, is always good for an uplifting tale about how glorious the postscarcity, anarchic, machine laden future will be.

\section{Souls, Heaven, and Hell}

Virtual Realities take a rather unique form in Surface Detail. In other Culture novels, it is suggested that VR is similar to any other science fiction setting: you log in and your imagination is the limit. One can do anything at any time they want and log out again whenever they feel like returning to the material world. It may seem an odd addition to a future-society such as the Culture where everything already is possible, and it is not suggested that there is much more to VR than what the Culture already has to offer. In spite of what the Culture wishes was true, other galactic civilizations do exist alongside it, and not all of them hold with the same principles or have the same technology level as the Culture does. Virtual Reality becomes a strangely metaphysical and religious experience especially in the highly technological societies. Virtual Reality is a realm that assuredly exists. It is both outside of and yet somehow still within subjective reality. Signals can be sent to your brain to make you feel as though you are interacting with a real world, but you are not. Nothing in the virtual universe is technically physically real. Surface Detail pushes the concept of Virtual Reality to its natural conclusion: the creation of virtual afterlives.

In many of these societies, immortality is entirely possible. However, sentiences that are born mortal will eventually want to die, and for those that are not ready to face what lies beyond there are the virtual afterlives. When a person dies in the Culture, they can choose to either be inserted into a brand new body to continue on with their lives, 
they can choose to keep on with dying, or they can choose to "die” and be sent to a virtual afterlife. In general, these reference the heavens, those that "offer everlasting fun for the post-dead," or those that are "as much for the benefit of those still living as the dead themselves, providing societies that had inherited or recently come up with the idea of consulting the ancestors," as well as the more contemplative heavens of a "philosophical nature” (Banks, 127-8). A person, once they have grown tired of living in a material plane of existence, may choose to "die” and stay "dead” until they grow bored or go insane or beg for true death. No society with access to the technology (save for the highly traditionalist ones) has any problems with letting its citizens "die” and, via the advent of soulkeeping technology, enjoy a virtual heaven for a while.

The "soul” is a given in The Culture. Even if it has no real religious significance, the citizens of the galaxy all acknowledge that there is a part of sentience that goes beyond the physical. There are several definitions of "soul" that are relevant to the ideas presented in Surface Detail. One of the Oxford English Dictionary's definitions includes, “a person's emotions, feelings, or thoughts; the moral or emotional part of a person's nature; the central or inmost part of a person's being” (OED, 2012). Basically, "soul” is defined as anything about existing that cannot be physically touched—-the things that are described as being "felt” (as emotions) or “thought.” In Surface Detail, souls are described in a safe, secular manner as "mind states" and "dynamic full-brain process inventories" (Banks, 66). All definitions seem to agree on something metaphysical. The term "consciousness" can be used interchangeably with "soul” in the context of the novel. Whichever definition is "correct," the idea that it is the core of the person and that it 
survives the physical body's death. More importantly, souls are saved and stored as digital information to be conserved perfectly in digital reality.

Preservation of a consciousness is done via "soul-saving technology" or “soulkeepers.” In the Culture, these devices are called neural laces. A lace begins as a planted seed in a physical brain and "grows with the brain it's part of, it beds in over the years, gets very adept at mirroring every detail of the mind it interpenetrates and coexists with” (Banks 78) to create a (probably) perfect copy of the host. In the event of the host's death or in the event of a traumatic brain injury that renders them dead enough for it to count, the consciousness can then be implanted into a brand new vat grown body that meets any specification the host desires. Thus, the body is rendered completely superficial. A host can theoretically change bodies as many times as it chooses to, or simply choose to exist, bodiless, in a virtual environment. The body in Surface Detail is thus othered from itself permanently, in that it is rendered completely irrelevant by societies possessing soulkeeper technology Corporeal presence does not carry the same weight that it used to in societies like the Culture. Rather, they favor of digitally uploaded minds, "participation in cyberspace is necessarily postcorporeal," posits Elain Graham. An uploaded mind allows for a self as "the master of pure knowledge," since the needs of the body become irrelevant. (Graham, 188). The instances of cyberspace we are privy to in Surface Detail are not concerned with achieving a pure mastery of knowledge. Rather, the impulse seems to be to continue acting on very human thoughts, imaginations, and desires. New knowledge does not seem to be sought. Instead, games are played, wars are fought, afterlives are joined, and bodies are switched. The ultimate freedom to literally do as you please within a virtual world is met with the limits of human imagination. 
In a society such as the Culture, the very idea of a virtual reality would seem just as irrelevant as the idea of embodiment. There is not much that a virtual reality can offer in cyberspace that the Culture cannot offer in physical space. Ultimately, this leads to speculation on why a virtual heaven is needed at all aside from the burden of actually being alive. Bodily death or brain death, though rare, can still occur in these hypertechnological societies, and if the choice is made for that body or physical brain to stay dead, the person only continues to exist as code in a server room somewhere. In effect, they are no longer human. Certainly, they experience the human burdens of thought and memory, certainly they still feel and they can certainly still operate within a body: but none of that occurs in material reality. For all intents and purposes, this person no longer exists—and yet, in the same strange space and thought-occupancy that virtual reality inhabits, they do still exist.

The Hells, on the other hand, "existed because some faiths insisted on them, and some societies too, even without the excuse of over-indulged religiosity” (Banks, 131). Sometimes the faith of a culture insists on an extant hell in order to keep its practitioners well behaved, it is similar for secular hells. Hells are punishment in a virtual world where all experiences and sensations might as well exist in material reality. It is heavily implied, if not outright stated, that no one chooses to go to hell. Hells, where they exist, are used as a scare-tactic. They act as incentive for citizens, hanging the threat of torment for thousands of subjective years over them to keep them from gross disobedience of the society's often harsh laws. The only trouble is:

...many species and civilisations objected profoundly to the very idea of Hells, no matter whose they were. A lot objected profoundly to the very 
idea of torture in any event and the practice of setting up Virtual Environments—-traditionally such dazzlingly fabulous realms of unmitigated pleasure—devoted to inflicting pain and suffering on sentient creatures seemed not just wrong but perverse, sadistic, genuinely evil and shamefully, disgracefully cruel (Banks, 132).

Not only is it wrong that the hells exist in the first place, it is even more heinous that they exist within Virtual Space, a (non)place that should be dedicated to joy and pleasure and doing whatever a mind can dream up. Being forcibly shoved into a realm where sadistic demons stretch your nerves across miles of burning sand is not typically anyone's idea of fun or carefree frolicking (forgive me if I am incorrect, I have no source to cite on this). Hells are "only rarely linked with other Afterlives, hellish or otherwise, and even then only under strict superveillance, and usually only with the aim of heightening the anguish of the sufferers by subjecting them to torments their own people somehow hadn't thought of” (Banks, 132). Pleasure, as it were, is freely shared across the universe, torment and anguish seems to be a much more private matter. Not only has the soul in question been dehumanized through death, it has been further othered through careful and copious torture.

Those confined to hell are not only the playthings of the demons uploaded there, but to those who decided to put them there. The demons are obvious, they are specifically chosen for their extreme sadism and copied and pasted throughout hell. The conservative senators, however, claim that the hells do not really exist. "We need the threat of punishment in the afterlife to keep us from behaving like mere beasts in this existence,” the senator claims (Banks, 275). He continues to claim that hell is only a threat. Those 
who take tours of hell are only watching a movie in 4D. The fact that we know that hell actually exists creates increasingly disturbing implications. We are never told what the senator's actual role is in hell. He may be one of the demons or he may get together with his friends to watch the torture over popcorn and whiskey. They know that the hells are fully functional. The sufferers are not people to those existing outside of the suffering. The victims are objects to be played with, tormented, and watched.

The tortured are just as affected as those causing the torture and watching it happen. Chay becomes so distraught in her journey through hell that she forgot that she was on a mission to prove that it actually exists. "That is just a dream," she claims, "just a dream. A treacherous dream. This is what is real” (Banks, 46). She has lost all sense of herself in the material world and has embraced herself as a string of code in a coded hell. The tortures are such that not only have outside forces completely dehumanized them, they have dehumanized themselves.

\section{Body Matters}

It is, perhaps, natural for a transcendental creation such as virtual reality to be applied to the transcendental creations that are afterlives. It seems natural that humans, who have always been curious about what lies after death, would try to simulate it once the technology is available. However, as Graham argues, “The absorption of corporeal presence into a purely digital embodiment may well suggest the effacement of the body, such that participation in cyberspace is necessarily postcorporeal” (188). If this is the case, then it seems that Banks is doing it all wrong. True, the "real" body is in no way necessarily involved with virtual space; however, the reader is never more aware of the body in Surface Detail than when the setting is in a VR. Considering the nature of Virtual 
Reality and the way it is used in this narrative in two separate dehumanizing aspects: post-death and war, this is not surprising.

The novel begins with a murder. This is quite shocking because, as the blurb on the back of the book tells us, the murder victim is the main character of the novel. There is no need to worry. A few chapters after her death we learn that Lededje, the victim, was uploaded into a conveniently nearby Culture mind (a hyperadvanced ship AIs who might as well be human). She, of course, does not know this. She wakes in a strange place, and the only clue she is given about her whereabouts is the word SIMULATION in the bottom of her field of vision. To her mind "the place looked perfectly, entirely real” (Banks 59). Not only does the room look real, it feels real: "SIMULATION, the word still said. She slammed one fist into the side frame of the mirror, felt pretty much exactly the amount of pain she would have anticipated, and sucked warm, fragrant air through her teeth” (Banks 60). Because of the highly accurate physical sensations she has experienced, she is not entirely convinced that she is actually in a simulation. Ultimately, what convinces her, and what unsettles her the most, is that what she sees in the mirror is not her "real” body. "While she still felt entirely like herself within herself...she was inside a body which was perfectly, flawlessly unmarked... No intaglia, no tattoo, no markage whatsoever” (Banks 61). As one of the intagliated, Lededje is defined by her physical appearance. She was modified in the womb, marked with a full body tattoo that covers not only her skin, but her eyes, teeth and organs. The tattoos mark her as an indentured servant, her purpose is to stand around in revealing clothing and look pretty. In the eyes of her society, she is an object. 
Almost the first thing Lededje realizes is that her body is not her own. The tattoo that marked her as an object is gone, leaving a lapse in her sense of self. Not only is this what convinces her that she is not home anymore, it acts as a cause of distress and anxiety. In his work “On the Soul,” Jean-Luc Nancy argues:

The soul is the body's difference from itself, the relation to the outside that the body is for itself. In other words... the soul is the difference from itself that makes the body...The soul is not specifically human, even if the human soul has its proper characteristics. Here it therefore has to do with the soul of every organized living body. The soul is the form of a body. (Nancy, 126)

The soul, according to Nancy, is its own sort of body. Whether it is a human soul or not, it is a part of existing. He acknowledges that it is not a physical body. Rather, that the soul comprises what is not the body, and the body is the material aspect of being.

It is already established that it is the soul or consciousness that gets transported into the virtual realm in Surface Detail. When Lededje looks into the mirror, she is seeing her soul made physical via code; the body of her soul. While she feels like herself within herself, the form she occupies at this point and her discomfort with it indicates that Lededje is not only intagliated and objectified physically, but she is in her mind as well. Similar to the victims of the Pavulean hell, she has cycled from being objectified by others into objectifying herself.

Lededje has never been much exposed to the Culture and was not aware that she even had a neural lace in her brain. She never expected to be vented into virtual reality upon her death, and so it only seems natural that she would latch on to the one thing that made her her: her body. One case does not make for much of an argument, however, 
Lededje's is not the only case of hyperawareness over the body in a virtual realm. Throughout the novel, we are privy to the many sordid adventures of Vatueil, a high ranking officer in the war effort to disband the hells from the universe. We later find out that all of his exploits take place in VR and in each one he inhabits a different kind of body with no knowledge (usually) of his previous encounters: all of which are uploaded to his master consciousness in some remote location.

Though we are never wholly certain about what each of his tasks accomplishes, we do know that his body is different each and every time. We also know that each time, just as Lededje is, he is extremely aware of said body. When he is first introduced he is “Conscript Vatueil, late of Their Highnesses’ First Cavalry, now reduced to Third Expeditionary Sappers," and we immediately know that he "wiped his sweating brow with a grimy, calloused hand. He worked his knees forward a few centimetres across the stony floor of the tunnel, sending fresh darts of pain up his legs” (Banks, 17). It does not stop there: throughout the chapter we have plenty of examinations of Conscript Vatueil's bodily complaints and conditions: "The exertion set off further stabs of pain, which ran up his back and across his straining shoulders," and, "The collision jarred his hands, arms and shoulders, setting his teeth on edge and ringing his aching back as though it was a bell. He almost cried out, but instead just sucked in a breath of stale, warm, humid air, pungently scented with his own bodily odours," and, "He'd felt ill since just after breakfast back and the surface and on the walk to the face. The last part especially, doubled over, had been a nightmarish slog of increasing nausea," and, "He was tall and his back hit more of the roof support beams than the other men's. He was developing what the long-serving sappers called back buttons; raised welts of hardened skin above 
each bone in his spine like giant warts” (Banks, 17-8) appear on the first two pages of the chapter alone. While the focus is largely on the aches and pains a sapper might feel, we are privy to the fact that there are also smells, and the beginnings of an effect that seems to imply several weeks, perhaps months of similar work.

Reading this chapter for the first time, we are not aware that any of this takes place within virtual space. Parallel to the chapter preceding it, Vatueil is tortured for information and then killed. We are left wondering if this is a book of vignettes about characters and their gruesome deaths until we meet Vatueil again, this time in an entirely new and different context. In a metanarrative, Vatueil has been uploaded into a robot which "had been built to fight," we also learn "The thing he was in was a thing, an 'it,' but he was not an 'it'; he was a he. He was a man... He was still who he was but he was also inside the thing, the machine that was designed and built to fight and perhaps get destroyed" (Banks, 115). Vatueil knows what he is now and knows who he was. These chapters parallel Lededje's uncomfortable journey outside of her own skin. Vatueil is more comfortable with the idea of body jumping, it is expected of him as a soldier. Still, the very fact that each of them notes that they feel like themselves within themselves but no longer inhabit the same body is significant. Bodies do not seem to even be important unless the owner is transported into one that is not their own. He is aware that he is not in the same body that he once inhabited and is able to make the distinction between "it" and "he."

Other bodies he inhabits are "a simulation of a creature, an organism designed to be at home in the pressure ice of a water world... He was not what he appeared to be," this is where "he was beginning to wonder if he ever had been" (Banks, 246). In this case, 
Vatueil seems perfectly aware that he is in a simulation, but it is here that he makes a poignant observation:

The ice inside the water planet did not really exist; neither did the water planet itself, nor the star or orbited nor the galaxy beyond nor anything of what appeared to be real no matter how far out you might think you were looking. Nor how far in you looked, either. Peer into anything closely enough and you would find the same graininess that the Real exhibited; the smallest units of measurement were the same in both realms, whether it was of time or extent or mass (Banks, 246). Everything, virtual and real, is created of the same building blocks, reinforcing Graham's observation that "Truth and reality are indistinguishable from illusion or simulation” (Graham, 191). Whether it is created out of code or out of actual flesh and bone, the molecular structure is still there. They may not be the same sorts of molecules, but they are there. In a VR you may experience an entire lifetime in the span of ten minutes, but time still feels as though it is passing a minute or an hour at a time. For instance, when trying to instill hope into Chay again, she one day wakes in the Refuge. In spite of nightmares, and her insistent atheism, Chay becomes one of the priestesses in the Refuge, working to copy manuscripts and sing hymns daily, for an entire lifetime until she grows old, becomes the Mother-Superior and eventually dies, only to be cast back into hell. Once she returns, she is changed, but it seems that no time has actually passed at all. She has subjectively experienced an entire lifetime or peace and contemplation, but once returned is more or less the same as before she woke in the Refuge. However, any time the setting is in the Real, the reader is never this aware of the physicality of a character. 
Since Vatueil is a soldier in the ongoing war, the spaces he occupies are necessarily battlefields. In his article, "Surgical Strikes and Prosthetic Warriors: The Soldier's Body in Contemporary Science Fiction," Steffen Hantke points out that "The battlefield (which we might assume these places are) tends to become a metaphor for a state of mind more than a distinct geographical or topographical designation” (496). When war becomes a focus point of Surface Detail, we are given virtual battle grounds in varying degrees of realistic probability. These places become metaphors for the collective thought processes of the war, or what the participants believe the war should be. They are not Vatueil's thought-processes, but those thought up by either side as a whole. The castle under siege, or the far reaches of space, or the terrifying non-spaces of hot-ice are direct representations of the state of war rather than actual geographical locations. While there might be a molecular structure to the battlefields, it still is not accessible to those walking the material plane. Hantke further expunges, "Since technology can literally move the battlefield anywhere, without consideration of the specific conditions of territory, war is now a possibility wherever we happen to find ourselves on the map” (497). Between the fictional speculation of Vatueil, and the real speculations of Hantke (appropriately) we can say that the boundaries between real and virtual are completely collapsed in this narrative. True, in order to achieve a virtual heaven, physical body or brain death must first occur. However, because of the technology, one cannot truly die unless they are permanently deleted. Somehow, with their consciousness still existing in the realm or molecular reality, like ghosts, they cannot move on, or at least that's the theory. No one seems troubled by the idea that when body or brain death does occur, the person might die anyway and "move on" unto the next realm, leaving only a copy behind. 
What, then, dies once the veritable ghost in the machine decides it doesn't want to exist anymore? Are there multiples of the same soul in the afterlife? We are never given the answers to these questions, death remains the ultimate unknown horizon.

Death creates something other than human, it creates a corpse that used to be human — the parts that make a living human alive are nowhere to be found. Ultimately, death cannot be known by the living, even virtual heavens and hells are not accessible to those who haven't chosen to die yet. War dehumanizes those who participate in it, even through history the lives lost appear as numbers on the pages of textbooks. Surface Detail dehumanizes the participants even further, placing them in strange bodies for strange missions for purposes that we never know. Both death and war occupy virtual spaces, thus relegating that which is no longer seen as human- the other- the virtual space. Though war is dehumanizing to the living, its aspects pale in comparison to the treatment of souls in the virtual hells.

We never get a real look into the heavens, knowing only what we are told in the beginning of the novel. After the narrative takes pains to tell us that hells are rarely shared across civilizations, we are given a very detailed look at one of them when a pair of concerned citizens hack into it in order to push their anti-hell movement along. The body, once again, plays an important role here, since much of the torture is physical. We find later that hell is a place of mental torment as well. The prospect of escape is dangled over those trapped. Ten may be taken to the gate, but only nine will be allowed to leave. Tours threatening those who are on the track to experience hell are floated over the landscape. Chay, the Pavulean that is left behind becomes an angel, allowed to offer deliverance to one person a day only. Hell, it seems, does not work without hope. A 
body needs to believe that they will someday get out of hell in order for hell to be effective. Every day a soul suffers is, in theory, one day closer to their release. A soul such as Chay cannot be affected by the various tortures that the Pavulean Hell has to offer because she has resigned herself to this existence. Torturing her is no longer "fun" for the greater demons involved because she has no expectation of ever escaping.

The one hell see is "In Valley 308, which was part of the Thrice Flayed Footprint district of the Pavulean Hell,” which just seems to be a location, but we learn:

The once very important person to whom the flayed hand belonged was still, in some sense, alive, and suffered every moment from having had their skin removed. They suffered in a magnified sense, too, concomitant with their pelt having been so grotesquely scale-exaggerated that a single ridge on one of their feet—or paws, there being some fairly irrelevant disagreement concerning the correct terminology — was now vast enough to form part of the landscape on which so many others lived their post-death lives and suffering the multitudinous torments which had been prescribed them (Banks, 45-6).

Not only is this hell a plane of blood-letting, rape, limb-breaking, nerve-flaying torture, but it is so creative as to have one of its inhabitants act as the landscape on which it all occurs. While it might be possible to look down at any once piece of scenery and identify one of the suffering beings there as having once been a person, it is less possible to do so when that person is literally the scenery. This hell occupies a warped animistic perspective. Normally, personalities are not attributed to the scenery. However, everything that exists in this vision of hell is alive and, in some sense of the word, a spirit. In general, animistic spirits have agency over their interactions with their human 
counterparts, mostly these beings are harmless, those in hell have no agency. The souls trapped in hell are subjected to unique forms of torture, no one prays to them or asks for favors from them. When they are not being tortured, citizens of hell are expected to fight for their arbitrarily chosen side. We are never told what happens to them if they do not, it is easy to assume that their torment grows even worse. So not only are those who are trapped in hell subject to the dehumanizing process of bodily torture, they are subject to the dehumanizing process of a pointless war. They become tormented soldiers, slaves to the greater demons, all while existing as a string of code in an unknown server room in the deepest reaches of space. 


\section{Chapter Three: The Oversaturation of Existence}

"Weren't we supposed to be getting deep-bio upgrades by the time I hit fifty? Why is the future always... in the future?" -Hamish Brookeman, Existence

Representations of the Post/Human refers to a published collection about what the future might look like. Graham notes, "There is nothing about the future of work, travel, or communication, and very little... concerned with curative medical applications outside of genetic therapies” (Graham, 156). Few of those who would consider reading such a magazine would care for anything but what lives of luxury might look like. Many science fiction novels, movies, and TV shows show us a future where robots do all of the heavy lifting and humans do not need to worry about where their food or fuel is coming from. Anything can be cured with the press of a button or the wave of a wand with a barely believable pseudo-scientific explanation. It is easy to see this post-scarcity trend continued in the works of Karl Schroeder or Iain M. Banks.

David Brin, however, is known for writing "hard” science fiction or science fiction which rings with a hint of "this could actually happen." His novel, Existence, acts as an example of what humanity could become in the next one hundred or so years, including a look at the lives of the impoverished and downtrodden in a world that cares about them even less than it did before. What the novel depicts is a fledgling future society on its way to the grander, more comfortable worlds of Lady of Mazes or even Surface Detail. Earth is on the cusp of possibly colonizing nearby planetary bodies while still being stuck in a rigid class system on an almost familiar global stage: the wealthy are at the top, making all of the choices and everyone else is trying to figure out how to make their way. It is a look at what we might become, and how we might react if First Contact 
comes in the form of a piece of alien equipment rather than an actual organic being. The answers are troubling and include everything from quiet, aristocratic espionage to kidnappings and riots, to vague overall confusion.

Though Existence is largely a story about First Contact with alien life, virtual reality has a major and often surprising role within its narrative. Virtual Reality plays a huge part in the lives of humans. The internet has gone from being colloquially called the "web" into being referred to as "the mesh," and rather than using touch screen smart phones to access it, the people of the not-so-distant future use smart glasses and contact lenses. Artificial Intelligence and Virtual Reality are almost inseparable from one another in this narrative. The "smart" objects that humans wear not only allow the world to be seen in captions and pleasing overlays, they also read visual and subvocal cues to anticipate what their users want and do their best to deliver. However, with the neoaristocracy at the top of the social pecking order, access to technology is limited by one's means to afford it. It seems to be expected that everyone has access to something, or that is at least the illusion. We get a good look at Earth through the eyes of characters from several class-based walks of life, from the impoverished scavenger, Peng Xiang Bin to the famously infamous (and possibly autobiographical) author Hamish Brookeman, to the up-and-coming journalist Tor Povlov to the wealthy aristocrat Lacey Donaldson-Sander and her son Hacker. We even get the viewpoints of alien machines and hyper-intelligent dolphins. The narrative spans not only their personal struggles with the news of First Contact, but the overall struggles of the mobs of humanity (or whatever species) that surround them. 
It is, if nothing else, an exceptionally fascinating look into what may or may not lie ahead for humanity.

Existence offers a further look into the paradox of VR; alienating and uniting at the same time. Yet there is something intrinsically hopeful about the novel. It seems to want to convince us that in light of the imminent failure of a thousand other alien species to survive long past their space-faring years, humanity has a chance to beat the odds of total annihilation. Humanity will have to evolve into something closer to The Culture in order for it to beat those odds, but the novel seems hopeful. However, in direct opposition to other VR-heavy narratives, the othering that occurs is not necessarily one of a complete loss of humanity, but an oversaturation of it. Where others may focus on the dehumanizing aspects of othering, very rarely is that fact that too much of anything is just as problematic as too little of it.

\section{From Vanity to Virtual}

New technology is often fetishized. Advertisements show us shiny, glamourous new devices being wielded by shiny, glamorous people leading shiny, glamorous lives. Existence has taken what Graham calls "the intimacy of connection, [and] the consummation of desire, and computers [being] erotically charged” (Graham, 171) a step further straight into narcissism. As fledgling reporter Tor Povlov walks through a marketplace with her smart glasses catching the technology-enhanced advertisements and the products they advertise, her thoughts veer to herself:

Tor couldn’t help doing a quick self-checkout, murmuring, “tsoosu.” Subvocal sensors in her collar translated—To See Ourselves as Others See Usand the inner surface of her specs lit with glimpse views of her, from several 
angles, crowding the periphery of her percept, without blocking the center view Tor needed to walk safely.

One image—from a pennycamera someone stuck high on a lamppostlooked down at a leggy brunette walking by, her long dark hair streaked with tendrils of ever-changing color...

Another tsoosu-vista showed her from ground level, smiling now as she passed a kiosk...It started with Tor's oval face, lingered briefly over her white smile, then caressed downward, appreciated every curve, even as she strolled away (13).

It is a testament to the vanity of the time that such a function even exists. There is a morbid curiosity following us to wonder what the world looks like from another's point of view. The ability to see through someone else's eyes might make us more humane if not necessarily more human. At the same time, Tor knows people like what they see when they watch her walk by, she takes pride in her relatively unaugmented appearance drawing gazes even in a time when beauty is cheaply acquired.

It is worth noting here, if nowhere else, a further insight from Elaine Graham: It is argued that contemporary digital technologies, such as virtual reality, are merely a continuation of human capacity for tool-making. What may seem unfamiliar and threatening is but an extension of perennial skills, serving not to undermine or expunge the human, but to enhance it, as tools have always done (185).

The logic is sound, human development is based upon what tools were created and used at any given time period, from fire to the wheel to the use of iron. There is no real reason 
to believe that virtual reality is anything but a tool, whether it is used to spread and receive knowledge or to pursue one's passions. It offers a freer and easier way of doing everything. Graham also mentions ways to "afford access into a group mind never before experienced” (170). Combine both of these sentiments and you get something similar to what Existence terms a "smart mob.”

We are first introduced to the concept when Tor is following a lead to put an end to a terrorist attack in progress. After sifting through enough rumors to try to eke out the truth, she calls on the power of public knowledge to aid her, "I request a smart-mob coalescence. Feedme!” (Brin, 161) she demands. Hundreds respond, converging into a collective intelligence that works on majority consensus. There is the condition that there might be nothing of note happening aboard the zeppelin at all. There is enough interest generated that voices gather and guide her through the process of investigating something that may or may not be going horribly, explosively wrong in Tor’s immediate vicinity.

Of course, Tor's place on the zeppelin does prove to be useful from a journalistic standpoint, as she is right there when everything goes up in flames. She barely survives and ends up as a charred husk, but continues chasing leads and stories through the mesh-or the web hyperevolved for the future. With the help of her smart-mob, now comprised of fans and experts alike, she is instrumental in uncovering the secrets and conspiracies surrounding the alien artifact that is central to the narrative. The smart-mob is, perhaps, the most unique use of virtual reality that I will discuss.

We learn, after Tor's brave decision to do so that "Calling up a smart-mob was tricky.” It is especially tricky in a situation such as the one she is in, because "People might already be too scattered and distracted by the rumor storm. The number to respond 
might not reach critical mass - in which case all you'd get is a smattering of critics, kibitzers, and loudmouths, doing more harm than good” (Brin, 162). In other words, a smart-mob might have practical uses on occasion if enough of the right people are around to join it. A dearth of people means that it could also go fantastically wrong. There is a trick to it; with the use of credibility, "you needed to attract a core group — the seed cell— of online know-it-alls...armed with the latest coalescence software, who were smart and savvy enough to serve as prefrontals... coordinating a smart mob without dominating” (Brin, 162). Basically, there needs to be a core group of people passionate about the subject you need a smart-mob for, in this case navigating a zeppelin (and later discovering secrets and possible alien reasoning), who are also not egotistical enough to need to overpower the expertise of a group consciousness with vapid individualism.

The collective consciousness is not an unfamiliar concept in science fiction novels, especially not those where alien-life is concerned. It is strange that collective consciousness is considered alien, since James O’Sullivan points out “The idea of collective consciousness... was adapted from real-world biological and sociological theory” (O’Sullivan, 80). Also termed ‘superorganism,' or 'hive mind ', Earthbound examples include ants, bees, some types of bacteria, and even a few animals. Less common is its association with human minds, though at its most broad definition, superorganism can also apply to entire ecosystems or human societies. A human society is usually not considered terribly alien as long as the human in question is living in it.

\footnotetext{
${ }^{1}$ There is a small difference between a hive mind and a collective intelligence or consciousness. Hive minds often act on the impulses of one queen organism while collective intelligences/consciousnesses rely on the various intelligent contributions of all of its members.
} 
However, a superorganism becomes strange once it gets narrowed down into a smaller cluster of human minds speaking with one voice.

In fact, in novels such as Ender's Game or Starship Troopers it is used as a device to show how alien the aliens are. They think and act in an entirely different manner than ourselves, the individual does not exist on the same scale, rather an individual is comprised of many minds. That, in itself, is telling when the usage is applied to human minds. A collective of individuals comes together and coalesces to create something new, something other that acts as a new form of consciousness: one meant to inform and to research with more credibility and accuracy than a single mind could accomplish... so long as the right sort of minds are at the core of it.

Existence, along with those that O’Sullivan cites in his article, “Collective Consciousness in Science Fiction,” share the sentiment that in a collective intelligence situation, "Establishing and maintaining any form of individualism is largely incompatible with the idea of a collective consciousness” (82). Indeed, once people begin to lose interest in Tor's mission to find out what's going on in her zeppelin, they leave and she remarks that the mob , "was starting to sound individualized and had even used the first person 'I'”' (Brin, 169). A smart mob, once created, gains a voice of its own. When it is large enough it refers to itself as “we,” but acts as a singular being. It is a difficult concept to wrap one's head around, but it is inevitably categorized as becoming the other. Even if smart mobs do not seem to be something alien to anyone in the narrative, the smart-mob is not human as such. It is made of humans, but the same could be said of a society, or a particularly grotesque leather coat. "Made up of humans” does not mean human, and while we are struggling to figure out just what human actually 
means, we somehow know that a collection of minds and voices forming one to make choices simply is not it.

The trend of leaping outside of one's self to become part of a greater whole follows Tor after she is nearly killed in a zeppelin explosion. Her brain is miraculously rebuilt, but she is confined to a container built for what remains of her flesh. After a period of self-pity as the scientists do their work to replace the neural connections her body lost in the explosion, Tor is able once again to resume her place as a truth-seeking journalist. In similar fashion to both Lady of Mazes and Surface Detail, with the benefit of once again being able to subvocalize, she is able to navigate the mesh with her now constant smart-mob. In much the same way that the sentient beings in Surface Detail must suffer brain death to access the heavens and hells, should they choose to do so, Tor must suffer a of physical near-death to exist almost purely in the realm of data. However, Tor must still be alive, science has advanced far enough that it can use experimental technologies to rebuild a brain, “soul savers” are not available to save Tor’s intelligence on a hard drive in a distant server room. "That notion has always been 99 percent fiction and 1 percent science...” Tor explains in one of her first written pieces as a cyborg (Brin, 224).Tor, though living, though the darling of the mesh because of her heroics, is ultimately a science experiment in corporeal reality and a ghost on the mesh.

With such unique fame comes the burden of fans posing questions to the famous. Tor answers some of them in her writing:

Some of you have asked about organ reconstruction. Skin grafts are an ongoing bone of contention between me and the docs — they hurt like hell. But with biojet printers to spray my very own restemmed cells onto 
layered scaffolds, all the simple, fibrous, and vasculated tissue can be grown—liver, spleen, and left lung—just like the vat-farmer raised that beetfish burger you had for lunch.

Vat-grown organs call strange pictures of mice with human ears growing on their backs to mind. Generally, the ears are not functional and are for aesthetic purposes. Tor's new parts are required to make a body function as a body. They are being bred as if they were genetically modified food fish. These, Tor needs to continue on as she is—riding the data-waves of the mesh to find a story. She does not look like a human body, though. She continues:

There's even talk of arm and leg transplants, if a reclam donor with my rare antigen type can be found. But I sense doubtful tones under their hopeful words, what with all the nerve damage I suffered. For certain I’ll never again have real eyes and ears. (It’s a wonder my skull protected what it did).

So what's the point? Shall I regain mobility by want-controlling a robotic walker? One of those hissing, clanking things? (Brin, 224).

Margrit Shildrick writes about the issue of ownership with regard to prosthetics in her article, "Re-Imagining Embodiment: Prostheses, Supplements and Boundaries.” She remarks that those who are recipients of transplants and prosthetics are constantly asking "to whom does this body part belong” (273)? Tor knows where her replacement organs come from, but she is not bothered by them because without them, she would be dead. She draws the line at aesthetically pleasing, but medically unnecessary limbs (similar to the aforementioned mouse-grown ears). Tor makes the decision to favor function over 
form, discarding her previous narcissism to embrace her new life as the inhuman other. She turns to the desire to spend her life as a working, sustainable brain to continue doing what she loves.

\section{It's all in the HardwAIre}

As is clearly evidenced by Tor's misadventure leading into her heroism, virtual reality does not exist without things. In Surface Detail and Lady of Mazes, the technology is directly implanted into the user's brain. In Existence the hardware to access the internet

(the mesh, as it is called in the novel) is still largely external. There are a few examples of persons with augmented eyes or brains, but they are far from the norm in the novel's timeline. For the moment they are limited to using smart glasses, goggles and, contact lenses. The lenses, in whichever form, are capable of creating overlays on the world and as tracking visual interest and brainwaves. In other words, a person must interact with an object, something inorganic and outside of itself, to access a world that is both outside of and on top of the corporeal world.

In Existence most of the virtual reality is backed by pseudo-AI. While not as sentient as they might be in an Asimov novel gone wrong, AIs are intelligent enough to interact with and sometimes even anticipate their users' needs and wants, going to far as to "tap... laryngeal nerves and transcribe" anything an author or reporter says or thinks (Brin, 30). Gone is the age of having excellent ideas just before going to sleep, just have your “digaissistant” keep track of everything for you to sift through later. Having your subconscious and subvocal commands tracked isn't the only thing they can do. "Music!" you can command, "Theme based on something by Elfman. Free-improve modulo, matching tempo to ambient sonic rhythms"(Brin, 79). If a person feels that they need a 
soundtrack for their life, they can command any number of famous composers or artists and the music will match surrounding sonic vibrations, offering an appropriate backdrop to something as simple as doing your homework.

Access to these technologies is, naturally, based on personal wealth and power. Earth has not reached the Lady of Mazes stage of indolence and free-for-all technology to keep the masses happy. One must still purchase the latest toy in order to keep up with the ever-changing trends with the continually updating technology and newer and newer virtual realities. The question that should come with the barrage of new technology is "Who is all of this for?" The answer is unsurprising, there is a clear emphasis on the luxuries of the future without any real focus on how much work has to be done or who is doing all of it. The wealthy bask in the freshly unwrapped plastic glow of new technology while everyone else struggles to keep up or shuns it altogether. Both sides are explored in Brin’s novel.

There is an aristocracy, a small elite group controlling all of the money and power in the world. Many of them seem benevolent, donating vast sums of money to passion projects involving the arts or sciences. It is implied more than once that the very top of the pyramid has access to technology that the rest of the world doesn't even know is possible. The hierarchy is clear, and it is evident that those at the top hold the firm belief that they should remain at the top. Lacey Donaldson-Sander, a member of this elite group muses, "Somebody had to guide the new era, so why not those who were raised and bred for leadership?” (Brin, 58) and later, she reasons “the species and planet would be better off guided by a single aristocracy, than by a fractious horde of ten billion short-tempered, easily-frightened “citizens” armed with nuclear and biological weapons”(Brin, 149). 
These read like desperate rationalizations, especially after reporters like Tor think "how out of touch you are," when interviewees remark, “Are you really that suspicious of the aristocracy?...how old fashioned” (Brin, 61) once they are faced with suspicion that the upper echelons will seek to monopolize any new tech or procedure that becomes available.

Since Brin’s neo-aristocracy controls access to technology, there must be someone to distribute all of it to. The tiers fall to celebrities like the author, Hamish Brookeman, down to the already mentioned Tor Povlov who is firmly in the middle class. Both Tor and Brookeman have no trouble accessing the tech that they need for their lives and livelihoods. On this pre-cyberpunk earth, there is an entire class of people who are unable to participate in the highly technological future. Brin covers the desperately impoverished with Peng Xiang Bin, the Chinese scavenger having only a, “Cheap and obsolete” tablet that was "originally mass produced for poor children” that Bin’s wife, Mei Ling, stole when she left her previous job. However, because of how outdated and worthless it is, “it was never even reported stolen” (Brin, 91). Even when voicing the hopeful fact that the government would have to provide a better tablet device once their child becomes old enough for school, "Xiang Bin felt less sure. Grand promises seemed made for the poor to remember, while the mighty forgot” (Brin, 91). Bin' hopeless musings recall the failure of the wealthy to keep any promises they make. None of the unanswered promises are ever addressed in the narrative, but Bin’s memory suggests that reneging on promises has happened before. It does not seem to matter, Bin and his family are members of a forgotten class: three in the millions just like them just trying to survive while the rest of the world is light years ahead. 
Bin chose to leave the life of tending to "little-emperors" in a nursing home in order to try to build a better life for himself, his wife, and his infant son. As a result, he is out of touch with the rest of the world. When breaking news hits that an alien artifact has been discovered he only knows that a vague something has happened, "when the surrounding crowd seemed to halt, abruptly, all around him,” and realizes these were people who had been linked-in with goggles, specs, tru-vus, or contact-zhones” (Brin, 93). Certainly, the news does not affect him as much as it would other people who have the time and the technology to be affected by alien artifacts. He has more important things to worry about, such as holding on to his small piece of property.

Everything and everyone including those with no access can have a caption, an advertisement, a witty comment, a note to someone who may never see it, or anything at all attached to them in various levels of VR. It is overwhelming to someone who has never before experienced it as it is to Bin's wife, Mei Ling once she is able to buy a pair of specs because "so much of the world lay beyond sight of normal eyes” (Brin,226). Mei Ling finds herself having to (re)learn how to use the specs, exploring each level to see what exists on it. She discovers a layer where anyone can eavesdrop “if people don’t care enough to set up a privacy block," and another layer where buildings become transparent (Brin, 228). Comments and advertisements can even eat upon themselves, “TOMORROW WELCOMES THE BOLD!” one such advertisement exclaims, “To which, a tagger had attached, in lurid vraiffiti, visible to anyone wearing specs—-And Next Tuesday Greets the Gullible!” (Brin, 97, bold mine). One can paint the world to look like a jungle or a fantasy landscape of castles and fairies. One can become lost in the augmented reality of their virtual overlay with their AI assistants whispering in their ears. 
However, unless you have the tools that allow a virtual overlay to be seen, you are stuck in the "gritty layer called reality" with the Bin family (Brin, 92).

Those, then, who are the most organic—or at least possessing the least technology, end up being completely ignored by those of the species who are turning to machines, and ultimately travelling on the path to become them. Even Bin, who is not a member of this hyper-technologized future, ultimately falls to technology. On a scavenging trip, he manages to find an egg-shaped object that turns out to be a second alien artifact. Because of inquiries he begins to make about selling his object, a secretive organization gives him an ultimatum: come with us or you and your family die. Taking the obvious route to keep his life, he is given compensation and outfitted with a new eye (or aiye). The new eye is one of the only physical augmentations we see in the novel. Much like his wife, Bin must learn to use his new technology. While it is implied that Mei Ling has used a pair of specs before, Bin has never had his eye replaced. Where one eye is still a normal, organic, meat-person eye, the other is a robot eye designed to adjust brightness and contrast and do many of the same things that specs or the new contact lenses are able to do in a fraction of the time.

The lesson is that all you have to do to participate in the rapidly growing technological future is find something unarguably remarkable and be targeted by potentially malicious para-government organizations. It is easy, anyone can do it, right? After Bin’s misadventure the impoverished disappear from the story, showing only Bin and his wife's struggles to remain among the living during the First Contact event while there are people willing to go to great and bloody lengths to get their hands on Bin and his artifact. They have achieved the status of "haves," leaving fellow "have-nots" to 
continue to have no idea what is happening on the global stage. No one cares what the poor are doing.

\section{Like Unto Gods}

The fact the overlay technology was thought up and implanted into a popular medium is a statement to the desperate desire to see our imaginations physically realized in material space. Imagination, since it is not a corporeal thing can be closely linked with the soul, which is all about a human that it not the physical body. At some point, they must combine to make a complete being. Jean-Luc Nancy claims that the connection happens "through the activity of ordinary life, and not through thought and imagination as isolated faculties” (Nancy, 138). The imagination cannot be connected to the body through imagination. The imagination cannot be connected to the body at all, it is "not a transubstantiation but a communication” (Nancy,141). Imagination does not replace or become the soul. The soul occurs via communication between the body and its actions rather than the body and its thoughts. Thought is a part of the soul, action creates it. The whole premise shifts when the imagination can be realized as easily as a thought: when everyday life becomes imagination and vice versa. The space that the body once occupied is now larger. So, too, is the space that the soul takes up. Man has almost become a god in his own world because of a more complete unification and communication of soul and body, resulting in the realization of thought and imagination into a nearly physical form. Brin shows us a stepping stool to overcome and throw off the chains of simple humanity and providing a route to immortality through the alien artifacts.

The artifacts pose a fascinating problem. The first artifact is found in orbit around Earth. The astronaut, Gerald Livingstone, is out on a trash run and takes a risk in pulling 
the new and mysterious object in so that it can be further studied. The scavenger Peng Xiang Bin finds the second one at the bottom of the ocean. As soon as these devices begin to make themselves understood, hundreds more that have been sent to Earth explode in a confusion of communication attempts. Once researchers figure out how to communicate with the beings that appear inside the devices, the first impression is that [the first device found by Livingstone] "it’s a goddamned chain letter!... Whenever a new race joins the community," the device explains, "it selects one individual of its kind to be copied into each new probe” (Brin, 323). The alien beings within the egg-shaped artifacts are all downloaded personalities, and they offer to teach humanity the secret of creating its very own probe. There is a catch: no species that has ever made probes has survived for very long past their deployment.

True, this is not the literal immortality of an eternal physical body. However, in similar fashion to what the afterlives of Surface Detail offer, a consciousness can be copied and installed into a device and rocketed through the far reaches of space in the hopes of finding another sapient race to convert. They are full, artificial intelligence copies of real personalities just like the afterlives of The Culture. Thomas Frentz posits, "If disembodied intelligence, pure brain with no body, anticipates the next evolutionary advance in human history, then artificial intelligence may well be the clearest form of this trajectory, the pathway humans must take on their way to disembodiment” (Frentz 61). The next evolutionary phase may well be the loss of body. Whether we transform into streams of data or into disembodied beings of soul and energy is irrelevant. What humanity has done in this narrative is forced the evolution. They, with the help of other species, have learned how to exist as fully realized consciousnesses without needing to 
have a physical body breathing and pumping blood for them elsewhere. Not only can a technically real person with thoughts and emotions and desires exist without a physical body, they can exist as a thousand different copies of themselves simultaneously.

Ultimately, humanity finds that the artifacts are not chain letters at all. Rather, the are viruses with the ultimate goal is the total annihilation of a given species. Humanity is much more clever than to fall for it, though. While they do end up using the technology to achieve immortality (so to speak), they do not "sneeze" them into space to infect other species. Rather, they create telescopes to orbit the edges of the solar system and keep watch, and warn, and begin a new universal age of prosperity. Not only have humans physically become more than themselves physically, they have managed to pull together and do something truly remarkable together. It is an evolution of both physical and mental proportions, and we can only hope that if such a situation were to actually occur that we here on Earth would do something similar.

Many of the things in the highly technological societies of science fiction many never come to pass—-some might not even be realistically possible. As a contemporary device, VR is already beginning evolve into something similar to the world of Existence. Objects such as Google Glass and the Oculus Rift are on the horizon to offer humanity something resembling the vast virtual landscapes of Lady of Mazes and Surface Detail. These tales that started out as fun and imagination may slowly be coming to pass.

However, like the fairy tales of older times, these narratives come with blazing warning signs attached to them, "Beware,” they say, "Your humanity is at risk.” That isn't to say that virtual reality should be shunned and thrown away. Cyberspaces offer us 
as a species easier and better ways to globally communicate and to share our ideas with others who may have different points of view or ways of thinking.

These three novels show the alienating effects that being handed whatever you want can have on a species. When there is nothing to strive for or fight against, people seem to stop talking to each other and elect to lose themselves flying over the rings of Saturn or choosing death over the continued lack of conflict that post-scarcity life implies. 


\section{List of References}

"alienate, v." 9 2012. OED online. Web.

Bailie, Brian. "Smart Mobs and Kennerth Burke." K.B. Journal 6.2 (2010): 1-8. EJournal.

Banks, Iain M. Surface Detail. New York: Orbit, 2010. Print.

Brin, David. Existence. New York: Tor, 2012. Print.

Brin, David. "Tomorrow May be Different." Exploring the Matrix. New York: Byron Preiss, 2003. 182-199.

Card, Orson Scott. Ender's Game. New York: Tor, 1991. Print.

Frentz, Thomas S. "Transcending Embodiment: Communication in the Posthuman Condition." Southern Communication Journal 79.1 (2014): 59-72. E-Journal.

Graham, Elaine L. Representations of the Post/Human. New Brunswick: Rutgers University Press, 2002. Print.

Hantke, Steffen. "Surgical Strikes and Prosthetic Warriors: The Soldier's Body in Contemporary Science Fiction." Science Fiction Studies (1998): 495-509. Print.

Haraway, Donna. "A Manifesto for Cyborgs: Science, Technology, and Socialist Feminism in the 1980s." The Norton Anthology of Theory and Criticism. New York: W.W. Norton \& Company, Inc., 2010. 2190-220. Print.

Hardesty, William H. "Space Opera without the Space: The Culture Novels of Iain M. Banks." Westfahl, Gary. Science and Beyond: the Frontier Theme in Science Fiction. Westport: Greenwood Publishing Group, Inc., 2000. 115-22. Book.

Hayles, N. Katherine. "From How We Became Posthuman: Virtual Bodies in Cybernetics, Literature, and Informatics." The Norton Anthology of Theory and Criticism. New York: W.W. Norton \& Company, Inc., 2010. 2165-87. Print.

Heinlein, Robert A. Starship Troopers. London: Penguin Books, Ltd., 1987. Print.

Nancy, Jean-Luc. Corpus. Fordham University Press, 2008. E-book.

Norman, Joseph. "Digital Souls and Virtual Afterlives in the Culture Series." The Transressive Iain Banks: Essays on a Writer Beyond the Borders. Ed. Martyn Colebrook and Katherine Cox. Jefferson: Macfarland \& Company, Inc., Publishers, 2013. 150-164. Book. 
O'Sullivan, James. "Collective Consciousness in Science Fiction." Foundation 39 (2010): 80-5. Print.

Schroeder, Karl. Lady of Mazes. New York: Tor, 2005. E-book.

Schroeder, Karl. Singular Interviews: Karl Schroder Michael Swanwick. August 2008. Print.

Shildrick, Margrit. "Re-imagining Embodiment: Prostheses, Supplements and Boundaries." Somatechnics 3.2 (2013): 270-86. E-Journal.

"soul." 3 2012. OED. Web. 2662014.

"Soul." 161 2014. Encycolpedia Britannica. Web. 2662014.

Spinks, C.W. "Myth, Semiosis, and Virtual Reality: Or Something Virtual Comes This Way." Semiotics (1993): 109-20. Print.

Wampole, Christy. "'Cyberia, Syberia...': Clones, Virtual Spaced, and Cyber-Seves in Claudio Magris's Alla cieca." MLN 129.1 (2014): 162-79. Journal. 